\title{
Damage Tolerance and Microscopic Study of GFRP
}

\section{Laminates}

\author{
Kalyan Kumar Singh \\ Department of Mechanical Engineering, Indian School of Mines (ISM), Dhanbad, India
}

\begin{abstract}
Glass fiber reinforced polymer matrix composites have poor translaminar properties which make them particularly susceptible to impact loads. In this research work, FRP laminates were prepared by different orientation of plies. In mode I test, a double cantilever beam specimen is employed to determine critical energy release rate, and in Mode II test, Interlaminar critical energy release rate is determined by employing an end notched flexure specimen. Modes I \& II fracture toughness are determined under static conditions and impact induced damage area of interface under impact conditions. For low velocity impact, damage starts with the creation of a matrix crack. In some cases the target is flexible and the crack is created by tensile flexural stresses in the bottom ply of the laminate. This crack, which is usually perpendicular to the plane of the laminate, is called a tensile crack. For thick laminate, cracks appear near the top of the laminate and are created by the contact stresses. These cracks, called shear cracks, are inclined relative to the normal to the midplane. The impact is made with a mild steel striker to induce impact energy at impact velocity close to $50 \mathrm{~m} / \mathrm{s}$. A circular Teflon sheet is introduced as a penny crack to facilitate failure on the mid-plane of the laminate. The DAE (Damage area extension) initiated by the pre-crack is observed to significantly modify the DAE as amount of XNBR (Carboxylated acrylonitrile butadiene) in the Epibond varied from different percentage. The microscopic analysis shows that the fibres are more damaged in symmetric laminate compare to any other type of laminate, because the centre of the laminate orientation is same in this laminates.
\end{abstract}

Key words: Composites, FRP, fracture toughness, interlaminar, interfacial cracks.

\section{Introduction and Literature Survey}

Interlaminar cracking is one of the predominant modes of damage in composite structures. The growth of the interlaminar depends on progressive stiffness degradation and eventual failure of the composite structures. Thus, the resistance to inter-laminar fracture toughness is an important composite property of great interest to structural design. The pre-cracks were developed with the help of epoxy resin. Epoxy resins are a class of versatile thermosetting polymers and are extensively used in structural adhesives for polymer composites. This is because of their high strength, low creep, very low cure shrinkage, excellent resistance to corrosion \& appropriate electrical properties. Many researchers were prompted to work towards the toughness properties of FRP.

Corresponding author: Kalyan Kumar Singh, Dr., assistant professor, research fields: advanced manufacturing, advanced composite materials, fracture mechanics and contact mechanics.
F. Frnesto Penado [1] calculated the fracture parameters at interfacial cracks in laminated composites. Depending on the applied loading and crack length, a contact region may develop that changes the nature of the resulting stress intensity factors and energy release rates with respect to open crack. Gouri C. et al. [2] studied the adhesive properties like lap shear strength and T-peel strength of novolac epoxy resin modified with carboxyl terminated butadiene acrylonitrile (CTBN) solid resin and cured with two different curing agents namely, dicyandiamide (DICY) and 3,3'-diaminodiphenyl sulphone (DDS) using aluminium adherends. Substantial improvements in adhesive properties were obtained by the inclusion of moderate concentrations (15-20\% by wt.) of CTBN in the formulations.

He J. et al. [3] studied the influence of tougher concentration on the behavior of two phase, rubber toughened epoxy. They showed that the toughness increased to a maximum and then decreased as the 
concentration is increased. Kumar P. and Singh R. K. [4] studied the impact damage area and interlaminar toughness of FRP laminate by modifying the epoxy resin with the addition of CTBN 1300X8 and triphethylphosphine under a controlled atmosphere of inert nitrogen gas. When impacted by a steel projectile they found a significant reduction in damage area. Zhang B L et al. [5] synthesized a series of novel toughening agents defined as LCEU containing both flexible chain and rigid rod like moiety and used to modify the epoxy resin (E-51)/dicyandiamide (dicy) curing system. They showed that the modification yielded good results and the impact strength was increased considerably. Imanaka $M$. et al. [6] investigated the crack propagation in epoxy adhesives filled with spherical silica using DCB (Double cantilever beam) specimens. As compared to unmodified epoxy bonded specimen the fracture toughness was found to be higher. Also, the fracture toughness was found to increase with particle size in the range of 6-30 $\mu \mathrm{m}$. Imanaka $M$. et al. also investigated the fracture toughness of rubber-modified epoxy bonded joints. Adhesively bonded $\mathrm{CT}$ and SENB specimen were tested. The crack extension was found to be very small and the J-integral value was found to increase with enhanced plastic deformation [7]. Ochi M. et al. [8] modified a bisphenol-type epoxy resin which had a mesogenic group in backbone moiety with reactive elastomer (CTBN). They found that toughness of epoxy resin was significantly increased with the addition of CTBN elastomer compared with that of bisphenol-A type epoxy resin [9]. Marieta C. et al. [10] used atomic force microscopy to determine the microstructure of thermosetting matrices toughened by incorporation of core shell particles and high performance thermoplastics. They used AFM to analyze the influence of modifiers and the curing conditions on the generated morphologies. Duncan and Dean proposed that the cavitation model accurately predicts the behavior of rubber toughened adhesives. Varley R. J. [11] evaluated three low viscosity polymers namely $\mathrm{CTBN}$, epoxy terminated hyper branched polyester and an aminopropyl-terminated siloxane. He showed that the epoxy terminated hyper branched polyesters can be used effectively to toughen the lower cross linked epoxy resin systems. Polymer composites have poor translaminar properties which make them particularly susceptible to impact loads [12]. Such damages are not detectable to the normal eye (the damage being in the substrate region or being too small to be visible to the naked eye), which adds to the critical nature of the low velocity impact damage [13]. Therefore, it has been a subject of particular attention of researchers worldwide. The available literature has concentrated mostly on two aspects. The first one deals with experimental and theoretical investigation of the effect of impact induced damage on the post-impact compressive strength [14]. The second aspect concerns the relationship between the impact energy and the size of damage area [15]. Choi H. Y. and Chang R. K. [16] predicted the shape and size of impact induced delaminations in cross ply and quasi-isotropic graphite/epoxy laminates using three dimensional solid brick elements. There are two kinds of interfaces in these laminates: (i) interlaminar interfaces between 00 plies of [016] adherend laminates and (ii) Adhesive interface between the two [00] adherends. Specimen is made by 32 plies of GFRP sheet.

\section{Experimental Procedure of Various Tests}

The specimens are tested with three kinds of tests to explore fracture toughness and impact induced damage area of an adhesively bonded interface.

\subsection{Fracture Toughness of Interface in Mode I}

The fracture toughness (GIc) of adhesively bonded interface under Mode I loading is determined by the standard technique employing a DCB. The specimen with initial crack length of about $40 \mathrm{~mm}$ is pulled under displacement control mode at a slow speed of $1 \mathrm{~mm}$ per minute till the crack grows by about 4-6 $\mathrm{mm}$. The machine is stopped and the crack is allowed to come to 
a point of arrest. The new crack length is noted with the help of magnifying glass and the specimen is gradually unloaded to zero load. The specimen is loaded again and the same is repeated for 5-6 times to obtain relation between (i) compliance and crack length and (ii) critical load and crack length. With proper data reduction using regression analysis the critical energy release rate of the adhesively bonded interface is determined.

\subsection{Fracture Toughness of Interface in Mode II}

A test setup with a end notch flex (ENF) specimen is employed to determine fracture toughness in Mode II (GIIc) of adhesively bonded interface. The adhesive interface is at the mid thickness of the specimen of $2 \mathrm{~L}$ length and the precrack length "a" is close to $L / 2$ but it should not exceed 0.69 L. The ENF specimen induces mode II fracture at its midplane and measures the fracture toughness of the adhesive interface. This test is conducted in the Instron 4505 Machine by loading the specimens in a standard three-point bending fixture. The specimen with a precrack is loaded at a crosshead speed of $1 \mathrm{~mm} / \mathrm{min}$ and the load-displacement curve yields the critical load and the compliance for each specimen. With proper data reduction, the critical energy release rate of the adhesively bonded interface under Mode II loading condition is determined.

\subsection{Impact Test}

A panel with adhesively bonded interface at its mid thickness is impacted by a striker with incident energy of $48 \mathrm{~J}$ through an air gun set up. A specimen panel of size $150 \times 150 \mathrm{~mm}^{2}$ is clamped to the specimen mounts with central unsupported area of $120 \times 120 \mathrm{~mm}^{2}$. The panel is normal to the axis of the barrel so as to have normal impact of the projectile on the FRP panel. A short projectile made of steel and with spherical nose is employed to impact the specimen. High pressure compressed air is filled in the reservoir of the air gun to a desired pressure and the compressed air is released quickly with the help of a solenoid. The high pressure compressed air accelerates the projectile in the barrel of the air gun. The velocity of the projectile is measured accurately just prior to the impact with the help of a laser beam and a receiving diode. The receiving photodiode is connected to a digital storage oscilloscope through an appropriate circuit. The laser beam is aligned to the center of barrel for accurate measurements. The laser beam falling on to the photodiode generates a 5 volts output of the circuit box. When the projectile cuts the laser beam the voltage drops to zero and the oscilloscope shows zero voltage during this period. As soon as the rear end of the projectile clears the beam, the voltage is restored. Thus the oscilloscope displays a pulse of time interval " $\mathrm{t}$ " that corresponds to time taken by the projectile length to clear the laser beam. Knowing the length of projectile, the velocity of projectile is $1 / t$. All the three quantities, mass, length of projectile and time duration are measured very accurately and incident impact energy is determined within $1 \%$ accuracy.

\section{Results and Discussion}

In Mode I test, the toughness of adhesively bonded interface GIc, is determined for all six candidates of symmetric laminates and toughness of interlaminar interface is determined for comparison. Average value of symmetric laminates is $\mathrm{G} 1 \mathrm{c}=930 \mathrm{~J} / \mathrm{m} 2 \&$ for average value asymmetric laminates is G1c $=842 \mathrm{~J} / \mathrm{m} 2$. In Mode II test, It is difficult to attain high crack speeds with the DCB specimen because the part of the specimen ahead of the crack tip is unstressed but for an ENF specimen loaded under three point bending, the specimen is deformed during crack propagation, allowing locally stored strain energy to flow continuously to the crack tip and, as a result, to produce high crack propagation speeds. Average value of Symmetric laminates G1Ic $=4945 \mathrm{~J} / \mathrm{m}^{2} \&$ average value of asymmetric laminates $\mathrm{G} 1 \mathrm{Ic}=1786 \mathrm{~J} / \mathrm{m}^{2}$. After the specimen was impacted, the impacted area was measured by the help of planimeter of both type of the specimen. It was found that damage area of symmetric 
laminate is $7.5 \mathrm{~cm}^{2}$ and damage area of asymmetric laminate is $9 \mathrm{~cm}^{2}$. It was noticed that the delamination area on the specimen was more on asymmetric laminate compared to symmetric laminate. Now the impacted panel trimmed into 8 small size of specimen. The eight small pieces were cut by the special fixture design and attached with the lathe machine. The cut cross-section is polished using different grade of emery papers. The length of separation cracks between plies is measured on the cross-section under the high magnification lens with the help of a scale. Now the different area was measured on different interface of the symmetric and asymmetric laminates. This study was supported by the microscopic study of the impacted area of the specimen. First of all, the specimen was prepared and polished for microscopic analysis. By looking the microstructure of the specimen, it was studied that only three cracks were visible on the damage surface. In case of symmetric, other than centre crack, two more cracks were visible on only one side, that side is away from the bullet heating surface. In case of Asymmetric laminate, other than centre crack, two more cracks were visible on both side of the centre crack.

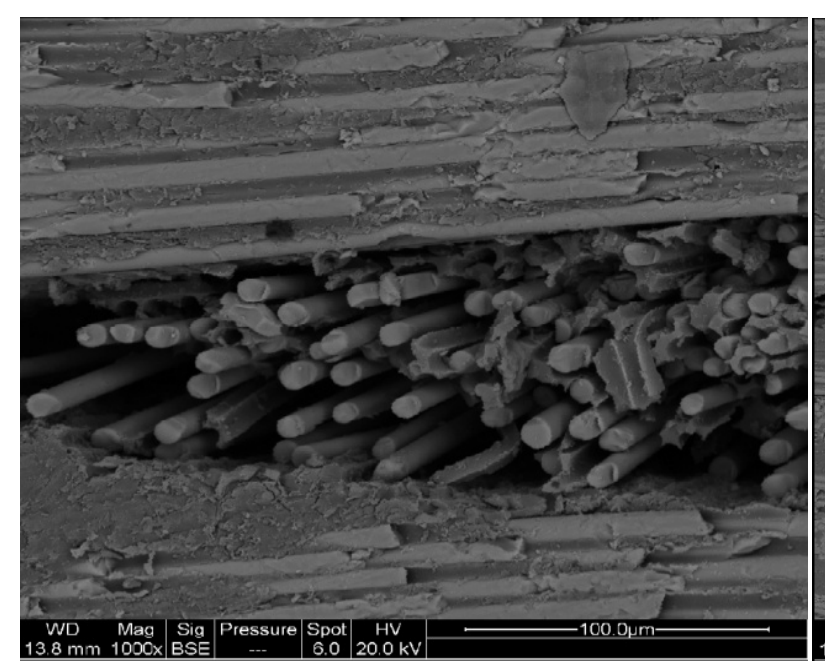

(a)

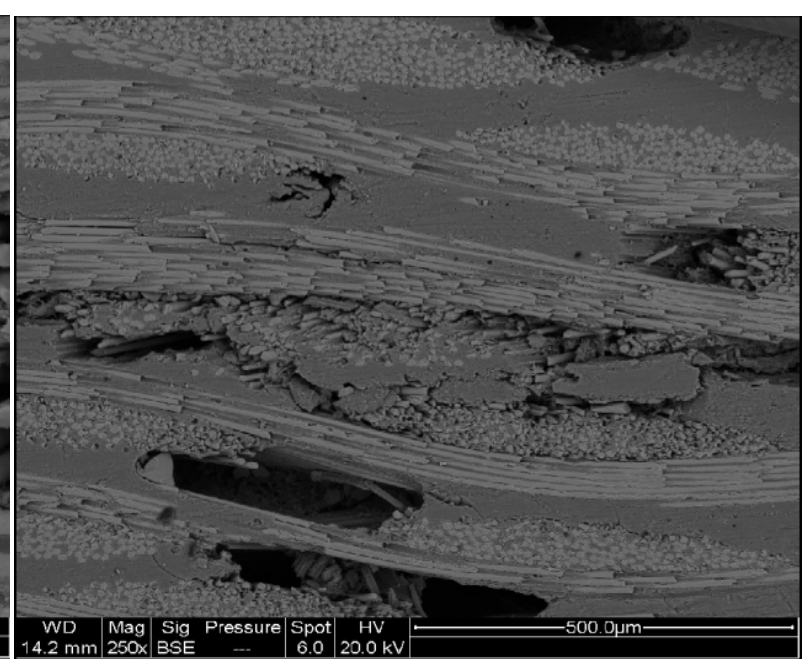

(b)

Fig. 1 Centre crack at (a) symmetric laminates and (b) asymmetric laminates.

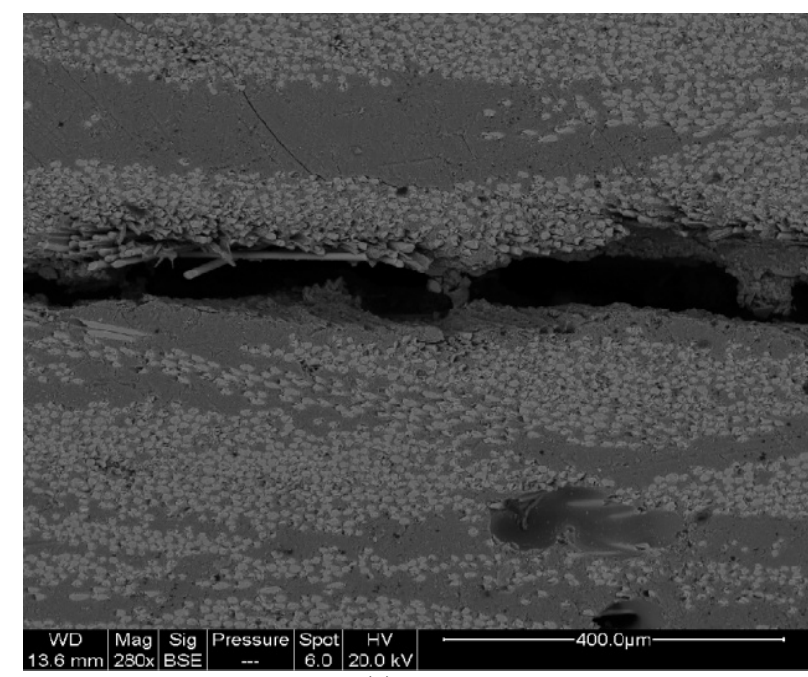

(a)

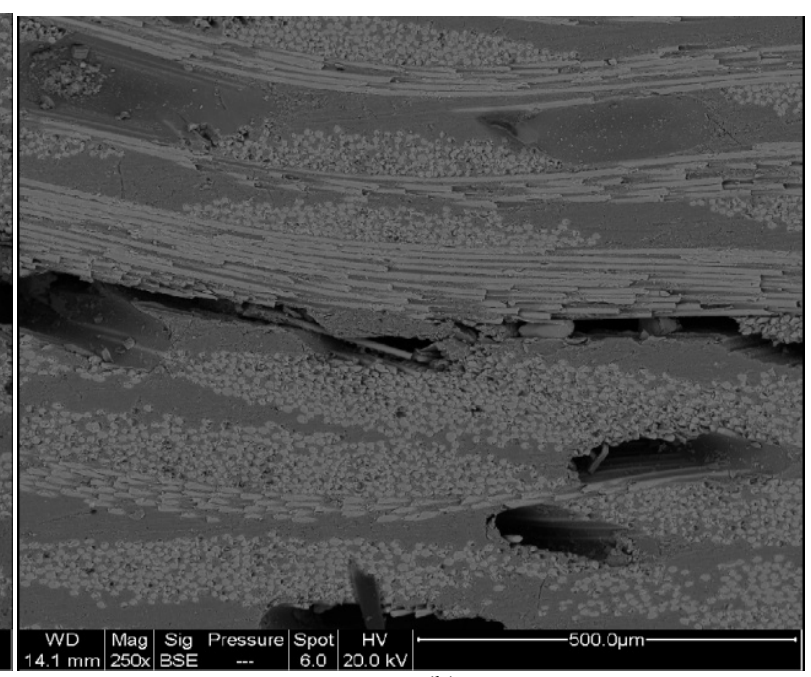

(b)

Fig. 2 First nearest crack of the centre crack at (a) symmetric laminates and (b) asymmetric laminates. 


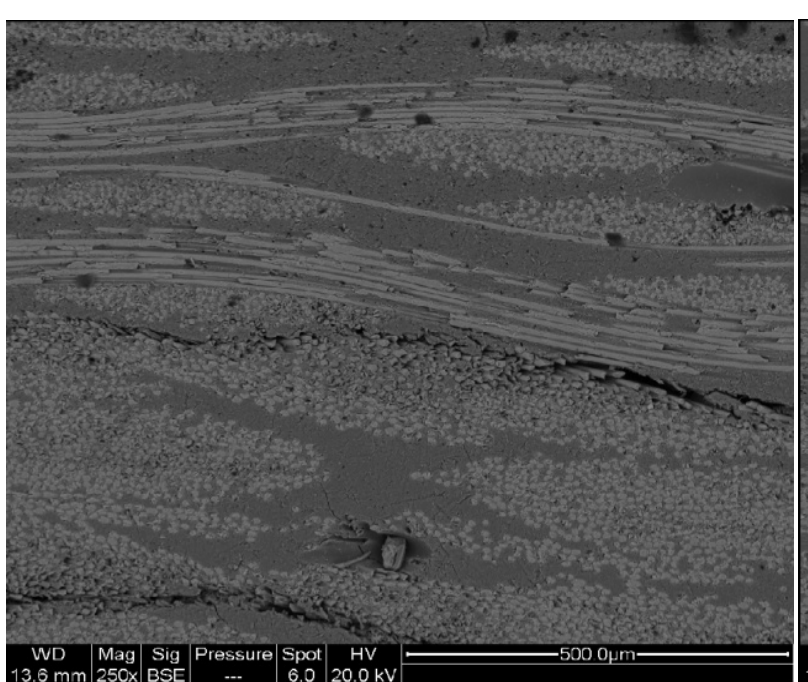

(a)

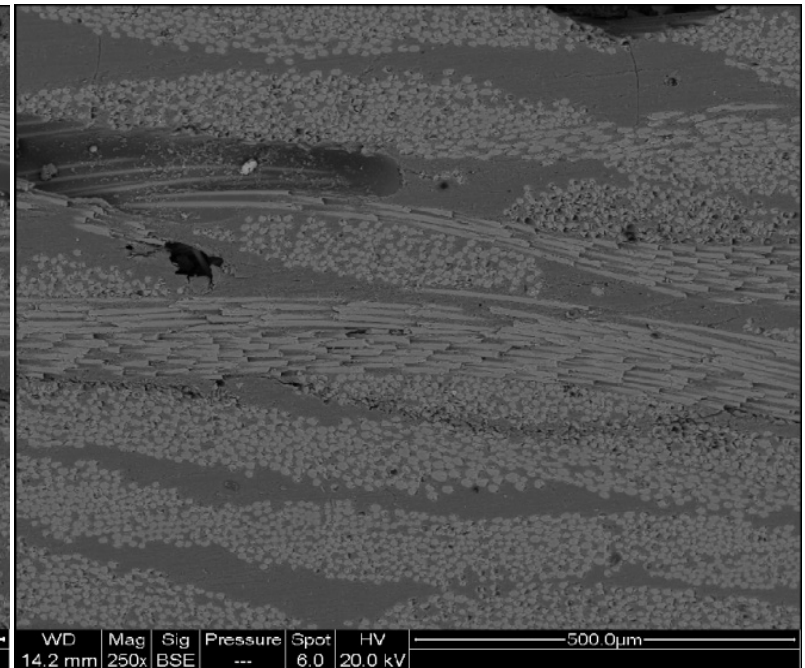

(b)

Fig. 3 Second nearest crack of the centre crack at (a) symmetric laminates and (b) asymmetric laminate.

\section{Conclusions}

The G1c \& GIIC were studied for symmetric laminate and asymmetric laminate. The external fibre crack is more on all three interfaces of asymmetric laminates compared to symmetric laminates. The symmetric laminates have high toughness values because crazes growing away from the interface into the polymers. The asymmetric laminates have much lower, and more realistic, toughness values, because in asymmetric laminates the cracks and crazes more along the interface. It was very interesting to know that, on the basis of SEM microstructure, fibre is more damage in symmetric laminate compare to asymmetric laminate, because in the centre of the laminate orientation is same in symmetric laminates. Symmetric have the better G1c \& GIIC compare to asymmetric laminates but damage tolerance capacity is not good enough compare to asymmetric laminates.

\section{Reference}

[1] Frnesto Penado, F. 2006. “A Computational Procedure for the Determination of Fracture Parameter at Interfacial Contact Cracks in Composite Laminates." Journal of Composite Materials 40: 701-15.

[2] Gouri, C., Ramaswamy, R. and Ninan, K. N. 2000. "Studies on the Adhesive Properties of Solid Elastomer Modified Novolac Epoxy Resin." International Journal of Adhesion and Adhesives 20: 305-14.
[3] He, J., Raghavan, D., Hoffman, D. and Hunston, D. 1999. "The Influence of Elastomer Concentration on Toughness in Dispersions Containing Preformed Acrylic Elastomeric Particles in an Epoxy Matrix.” Polymer 40: 1923-33.

[4] Kumar, P. and Singh, R. K. 2002. "Impact Damage Area and Interlaminar Toughness of Modified FRP Laminates." Advanced Composite Materials 9: 77-88.

[5] Zhang, B. L., Tang, G. L, Shi, K. Y., You, Y. C., Du, Z. J. and Yang, J. F. et al. 2000. "A Study on Properties of Epoxy Resin Toughened by Functionalized Polymer Containing Rigid, Rod like Moiety." European Polymer Journal 36: 205-13.

[6] Imanaka, M., Yoshinobu, N., Nishimura, A. and Takeo, I. 2003. "Fracture Toughness of Rubber-Modified Epoxy Adhesives: Effect of Plastic Deformability of Matrix Phase." Composite Science and Technology 63: 41-51.

[7] Varley, R. J., Hodgkin, J. H. and Simon, G. P. 2001. "Toughening of Trifunctional Epoxy System, Part VI: Structure Property Relationships of Thermoplastic Toughened System.” Polymer 42: 3847-58.

[8] Ochi, M., Morishita, T., Kokufu, S. and Harada, M. 2001. "Network Chain Orientation in the Toughening Process of the Elastomer Modified Mesogenic Resin.” Polymer 42: 9687-95.

[9] Chikhi, N., Fellahi, S. and Bakar, M. 2002. "Modification of Epoxy Resin Using Reactive Liquid (ATBN) Rubber." European Polymer Journal 38: 251-64.

[10] Marieta, C., Remiro, P. M., Garmendia, G., Harismendy, I. and Mondragon, I. 2003. "AFM Approach toward Understanding Morphologies in Toughened Thermosetting Matrices." European Polymer Journal 39: 1965-73.

[11] Varley, R. J. 2003. "Toughening of Epoxy Resin Systems Using Low-Viscosity Additives." Polymer International 
53: 78-84.

[12] Hosur, M. V., Karim, M. R. and Jeelani, S. 2003. "Experimental Investigation of the Response of Stitched/Unstitched Woven S2-Glass/Epoxy Composites Under Single and Repeated Impact Loading." Composite Structures 61: 89-102.

[13] Sankar, B. V. 2000. "The Effect of Stitching on the Low Velocity Impact Response of Delaminated Composite Beams.” Composite Science and Technology 60: 2681-91.
[14] Abrate, S. 1998. "Impact on Composite Structures." Cambridge University Press.

[15] Abrate, S. 1991. "Impact on Laminate Composite Materials." Appl Mech Rev 44: 155-90.

[16] Choi, H. Y. and Chang, R. K. 1992. "A Model for Predicting Damage in Graphite/Epoxy Laminated Composites Resulting from Low Velocity Point Impact." Journal of Composite Materials 26: 2134-69. 